\title{
Microbial Reduction of Cholesterol to Coprostanol: An Old Concept and New Insights
}

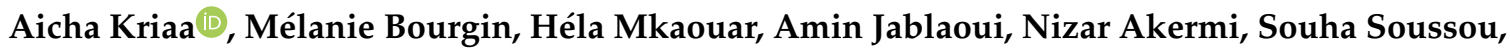 \\ Emmanuelle Maguin and Moez Rhimi *
}

UMR 1319 Micalis, INRA, Microbiota Interaction with Human and Animal Team (MIHA), AgroParisTech, Université Paris-Saclay, F-78350 Jouy-en-Josas, France; aicha.kriaa@inra.fr (A.K.); melanie.bourgin@inra.fr (M.B.); hela.mkaouar@inra.fr (H.M.); amin.jablaoui@gmail.com (A.J.); nizar.akermi@inra.fr (N.A.); souha.soussou@inra.fr (S.S.); emmanuelle.maguin@inra.fr (E.M.)

* Correspondence: moez.rhimi@inra.fr; Tel.: +33-1-3465-2294

Received: 23 January 2019; Accepted: 2 February 2019; Published: 8 February 2019

\begin{abstract}
The gut microbiota plays a key role in cholesterol metabolism, mainly through the reduction of cholesterol to coprostanol. The latter sterol exhibits distinct physicochemical properties linked to its limited absorption in the gut. Few bacteria were reported to reduce cholesterol into coprostanol. Three microbial pathways of coprostanol production were described based on the analysis of reaction intermediates. However, these metabolic pathways and their associated genes remain poorly studied. In this review, we shed light on the microbial metabolic pathways related to coprostanol synthesis. Moreover, we highlight current strategies and future directions to better characterize these microbial enzymes and pathways.
\end{abstract}

Keywords: cholesterol; coprostanol; reduction reaction; bacteria; metabolic pathways

\section{Introduction}

With more than $31 \%$ of all global deaths, atherosclerotic cardiovascular disease is now largely recognized as a major concern for global health [1]. A key risk factor for cardiovascular disease includes imbalanced blood cholesterol levels, notably a high serum concentration of low-density lipoprotein cholesterol [2]. Maintaining cholesterol homeostasis is achieved by balancing dietary cholesterol intake through its synthesis, absorption, and excretion [3].

Current therapeutic approaches aiming at reducing plasma cholesterol levels in humans rely on (i) the inhibition of cholesterol biosynthesis, (ii) an increased elimination of cholesterol from tissues into the intestinal lumen, and (iii) the reduction of cholesterol absorption from the gastrointestinal tract (GIT) [4-6]. While these three approaches seem attractive, they display several limitations including a significant proportion of non-responders among patients (20-30\%), and the omission of the intestinal microbiota impact on cholesterol cycle [7]. On a daily basis, around $1 \mathrm{~g}$ of cholesterol from diet, bile, and desquamated intestinal cells reaches the human colon. This cholesterol amount is metabolized by commensal bacteria to coprostanol [8]. Unlike cholesterol, coprostanol is poorly absorbed by the human intestine [9]. For this reason, it was suggested to have an impact on cholesterol metabolism and modulating serum cholesterol levels [8]. This takes more importance if we consider the existence of an inverse relationship between plasma cholesterol levels and the ratio of cholesterol to coprostanol conversion in the feces [10]. Indeed, cholesterol displays chemical behaviors different from coprostanol, which confer to the latter a feeble intestinal absorption [9]. Cholesterol conversion to coprostanol could therefore constitute a new strategy, allowing a better management of cholesterol homeostasis in humans without influencing host physiology [8]. Notably, some studies reported that cholesterol metabolites could be associated with procarcinogenic effects and an increased risk of colon 
cancer [11,12]. The reduction of cholesterol to coprostanol and the properties of this reaction remain largely unknown. This concept is still poorly understood, as few studies are available regarding cholesterol-metabolizing bacteria and their associated genes. Therefore, achieving a molecular characterization of these bacterial pathways represents a challenge in this field of research in setting out new hypocholesterolemic strategies.

In this review, we provide an overview of cholesterol and coprostanol chemical behaviors, and outline the coprostanoligenic bacteria. Moreover, we analyze the current knowledge related to the reduction of cholesterol to coprostanol, and highlight available approaches and future opportunities to better characterize these metabolic pathways.

\section{Cholesterol versus Coprostanol}

\subsection{Chemical Behaviors}

Cholesterol, a major sterol in body tissues, was first discovered in solid form in gallstones and bile [13]. It is a complex lipid substance that plays a key role in many biochemical processes [14-16]. From a structural point of view, cholesterol $\left(\mathrm{C}_{27} \mathrm{H}_{46} \mathrm{O}\right)$ is mostly a hydrophobic molecule that has a rigid, steranic core coupled to a hydrophilic hydroxyl group at position 3 . Such a unique structure is composed of four, fused hydrocarbon rings: A, B, C and D (Figure 1). Its physicochemical properties confer an amphiphilic nature and a specific orientation (i.e., A/B ring: trans) adapted to its integration into cell membranes $[17,18]$. Most plasma cholesterol exists in an esterified form (with a fatty acid attached at C3), making the molecule even more hydrophobic [19]. Cholesterol ester is the form of storage under which cholesterol is found in most tissues and plasma [19]. As a main structural component of cell membranes, cholesterol regulates membrane fluidity and cellular signaling, and serves as a precursor of important molecules including steroid hormones (e.g., progesterone, estrogen, etc.), vitamin $\mathrm{D}$, and bile acids [20].

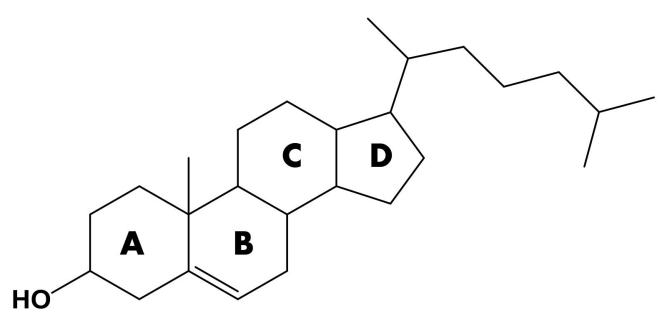

Cholesterol

(5-cholesten-3- $\beta$-ol)

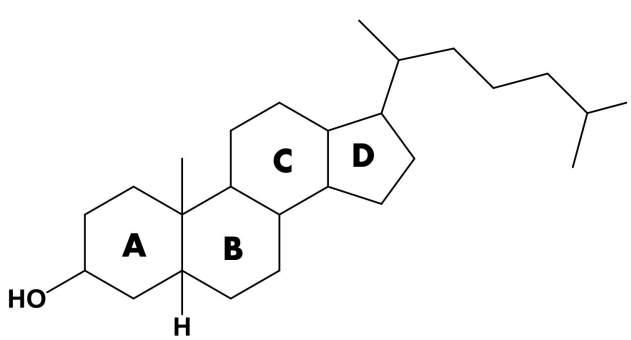

Coprostanol

(5- $\beta$-cholestan-3- $\beta$-ol)

Figure 1. Chemical structures of cholesterol (Molecular weight (Mw): 386,654 g/mol) and coprostanol (Mw: 388,6756 g/mol).

Coprostanol, a saturated analog of cholesterol, was first isolated in the mid-1800s and characterized as an alcohol $\left(\mathrm{C}_{27} \mathrm{H}_{48} \mathrm{O}\right)$ [21]. This sterol shares the same basic structure as cholesterol, but it lacks the 5- 6 double bond and it has an additional hydrogen atom at position 5 . This gives different properties to the sterane nucleus, making it less rigid (Figure 1) [21]. At room temperature, coprostanol is a white crystalline solid with a melting point of $101^{\circ} \mathrm{C}$ [22]. Like cholesterol, coprostanol is highly soluble in hexane, benzene, and chloroform. However, both sterols are insoluble in polar solutions like methanol [22]. The solubility of such sterols in alcoholic solvents increases with an increasing chain length of the alcohol-hydrocarbon moiety [23]. Accordingly, they tend to be more soluble in ethanol, but completely soluble in butan-1-ol [23]. Notably, cholesterol is insoluble in water at concentrations less than $1 \mu \mathrm{g} / \mathrm{mL}$ at $30^{\circ} \mathrm{C}$ [24]; nevertheless, no report exists on coprostanol solubility. 
Unlike most saturated sterols found in nature, which are A/B-trans, coprostanol seems to be the only exception with a cis-oriented A/B ring structure (the 3-hydroxyl group in coprostanol is in an equatorial configuration on ring A) [25]. The biological role of this compound remains to be elucidated.

\subsection{Intestinal Uptake}

The poor absorption of coprostanol in the intestine was associated with its very low uptake through the intestinal mucosa and its limited esterification in mucosal cells [9]. Indeed, the cis-A/-B ring structure in coprostanol, driving the difference in the 3-hydroxyl group from the axial to equatorial position, was suggested to affect coprostanol incorporation into mucosal cell membranes, thereby limiting its intestinal uptake [26]. Hence, a high-efficiency conversion of cholesterol to coprostanol was proposed to lower serum cholesterol levels [27,28]. Cholesterol absorption takes place mostly in the upper GIT [29,30], while coprostanol production occurs essentially in the large intestine [31]. This concept remains highly controversial, as earlier studies revealed the presence of significant amounts of coprostanol in the first half of the small intestine in rats [32,33] and humans [34].

\section{Microbial Conversion of Cholesterol to Coprostanol}

\subsection{Coprostanoligenic Bacteria}

Cholesterol conversion to coprostanol by intestinal bacteria was first reported in the 1930s [35]. Since coprostanol was not detected in tissues, but mainly in larger amounts in feces (more than $50 \%$ of total sterols in humans), this product was proposed to derive from bacterial conversion in the intestine [35,36]. A key role for the gut microbiota in this biotransformation was further investigated by comparing fecal sterols of conventional and germ-free rats. In fact, contrary to the conventional group, germ-free rats excreted only unmodified cholesterol [37]. These data provide evidence for the role of gut microbiota in cholesterol metabolism, including coprostanol synthesis. Numerous reports were aimed at identifying bacteria that were able to reduce cholesterol to coprostanol [38-43]. As anaerobic strains are difficult to culture, only few coprostanoligenic bacteria were isolated from rat cecal contents [38], baboons [40], and human feces [44,45]. Surprisingly, most strains exhibited similar properties and were assigned to the genus Eubacterium [40-44], except Bacteroides sp. strain D8 [45]. Bacteria belonging to Bifidobacterium, Clostridium, and Lactobacillus were also reported to reduce cholesterol to coprostanol in vitro [46-48], yet they were not explored in vivo. Based on metagenomic analysis, new bacterial phylotypes from Lachnospiraceae and Ruminococcaceae families were recently associated with high coprostanol levels in healthy humans [49]. Notably, associations of these bacterial taxa with coprostanol levels require further functional studies in order to elucidate the eventual causal relationship between these microbial communities and coprostanol synthesis.

\subsection{Two Patterns Cepending on Gut Microbiota}

In humans, microbial conversion of cholesterol to coprostanol is bimodal, with a majority of high producers (almost complete cholesterol conversion) that display low cholesterolemia and a minority of low, or inefficient, producers (coprostanol content representing less than one-third of the fecal neutral sterol content) [50,51]. Such conversion patterns were found to be equally distributed with respect to sex, and were independent of age [51-53]. Factors affecting cholesterol conversion were defined and proposed to be closely related to the abundance of cholesterol-metabolizing bacteria $[39,46]$. In fact, low converters harbored less than $10^{6}$ cholesterol-metabolizing bacteria per gram of stool, while more than $10^{8}$ cholesterol-metabolizing bacteria per gram of stool led to nearly complete cholesterol conversion [52]. Remarkably, Sekimoto et al. (1983) reported the existence of an inverse relationship between serum cholesterol levels and the coprostanol/cholesterol ratio in feces [9]. These findings denote that the conversion of cholesterol into coprostanol can significantly decrease the blood cholesterol level. A correlation between fecal microbial community structure and the conversion rate of cholesterol to coprostanol was also reported [46]. Interestingly, the high density of bacteria 
in the colon can explain the significant production levels of coprostanol seen in this part of the GIT. In fact, we previously reported the identification of the first human bacterium (Bacteroides sp. D8) that displayed a high coprostanol production level in human feces $[45,54]$. Furthermore, feeding the cholesterol-reducing bacterium Eubacterium coprostanoligenes significantly reduced plasma cholesterol levels in hypercholesterolemic rabbits [27]. Accordingly, greater coprostanol/cholesterol ratios were detected in the digestive contents of bacteria-fed rabbits [27]. Such effect was further ascribed to the reduction of cholesterol to coprostanol in the intestine, seeing that $E$. coprostanoligenes colonized and reduced cholesterol in the jejunum and ileum (sites for cholesterol absorption) [27]. The progress in functional knowledge related to the human gut microbiota, and the availability of new microbial culture facilities, offer a unique opportunity to isolate new coprostanoligenic bacteria belonging to different taxa.

\subsection{Metabolic Pathways}

The mechanism of cholesterol conversion to coprostanol was investigated and three major pathways were proposed [38,55-58]. The first one is a direct, stereospecific reduction of the 5,6-double bond of cholesterol, without an intermediate formation of a ketone at C3 (Figure 2) [59,60]. This statement was supported by the use of labeled cholesterol that led only to coprostanol synthesis $[59,60]$. The second one is an indirect pathway, which was described through the action of several bacteria on marked cholesterol (Figure 2). In fact, it was reported that cecal rat contents (Eubacterium strain, E. coprostanoligenes, and Bacteroides sp. D8) incubated with labeled cholesterol allowed for the production of cholestenone and coprostanone intermediates, demonstrating that this microbial pathway involved at least three steps $[45,61,62]$. The third pathway consisted of the isomerization of cholesterol to allocholesterol, which can be reduced to coprostanol by Eubacterium ATCC21, 408, and 403 species $[38,57,58]$. However, few data exist regarding this last bacterial metabolic pathway.

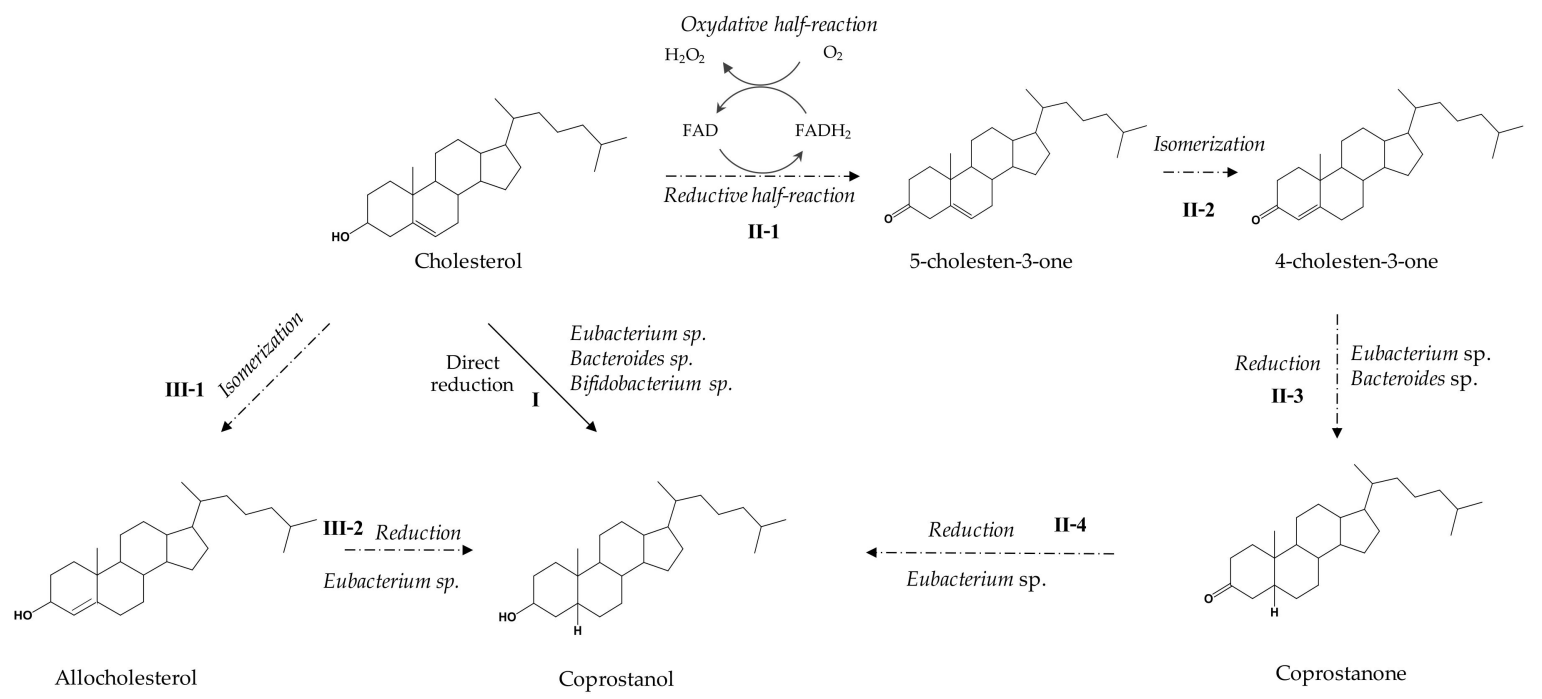

Figure 2. Metabolic pathways for cholesterol conversion to coprostanol. I: direct pathway; II: indirect pathway; II-1: Oxidation of the 3- $\beta$-hydroxyl group moiety catalyzed by cholesterol oxidase; II-2: Isomerization of $\Delta 5$ double bond to $\Delta 4$ by cholesterol oxidase; II-3: Reduction of the $\Delta 4$ double bond by 3-oxo- $\Delta 4$-steroid $5 \beta$-reductase; II-4: Reduction leading to coprostanol; III-1: Isomerization of cholesterol to allocholesterol; III-2: Reduction to coprostanol.

The first two steps of the indirect pathway are catalyzed by a single enzyme, cholesterol oxidase (EC 1.1.3.6), and result in the formation of 4-cholesten-3-one with a reduction of oxygen to hydrogen peroxide (Figure 2). Briefly, the 3- $\beta$-hydroxyl group of the steroid A ring is first oxidized to the corresponding ketone using the FAD (Flavin Adenine Dinucleotide) cofactor, which is reduced during this process (reductive first-reaction). Since the 5-cholesten-3-one intermediate is not stable and 
susceptible to radical oxygenation, the $\Delta 5$ double bond in the oxidized steroid ring is then isomerized to $\Delta 4$ to form 4-cholesten-3-one, the final steroid product. During the oxidative half-reaction, the FAD is finally re-oxidized by dioxygen to form hydrogen peroxide (Figure 2) [63,64]. To efficiently catalyze both reactions (oxidation and isomerization), distinct and essential features are required for cholesterol oxidase. As a starting point, the substrate (cholesterol) must be properly oriented to the cofactor to allow for hydride transfer from the steroid C3 site to the N5 site of the cofactor [64]. Then, during the dehydrogenation step a base is needed to: (i) deprotonate the steroid $\mathrm{C} 3-\mathrm{OH}$, and (ii) transfer protons during the isomerization reaction [64].

Biochemical and structural studies were performed for cholesterol oxidases of several microorganisms, mostly deriving from soil [65-69]. Structural studies revealed the existence of two forms of cholesterol oxidases: one with the FAD linked covalently to the enzyme, and another with the FAD non-covalently bound [64]. Despite topological differences in these two forms, both enzymes exhibit a large buried hydrophobic pocket, able to accommodate the steroid substrate (Figure 3). In both forms, the binding site for cholesterol is sealed off by a number of amphipathic loops to prevent potential aggregation. Once opened, these loops allow the sterol to exit from the membrane so that the 8-carbon isoprenyl tail of cholesterol can pack and bind to the protein [64]. Following substrate binding, hydrophobic interactions between cholesterol and hydrophobic residues minimize energy loss. Two active-site residues, Histidine and Glutamate, were shown as important to catalyze the oxidation and isomerization reactions (Figure 3). The Histidine residue binds to the $\mathrm{C} 3-\mathrm{OH}$ of the steroid, allowing for proper positioning of cholesterol relative to the FAD cofactor. Glutamate acts as a base during the isomerization reaction $[70,71]$.

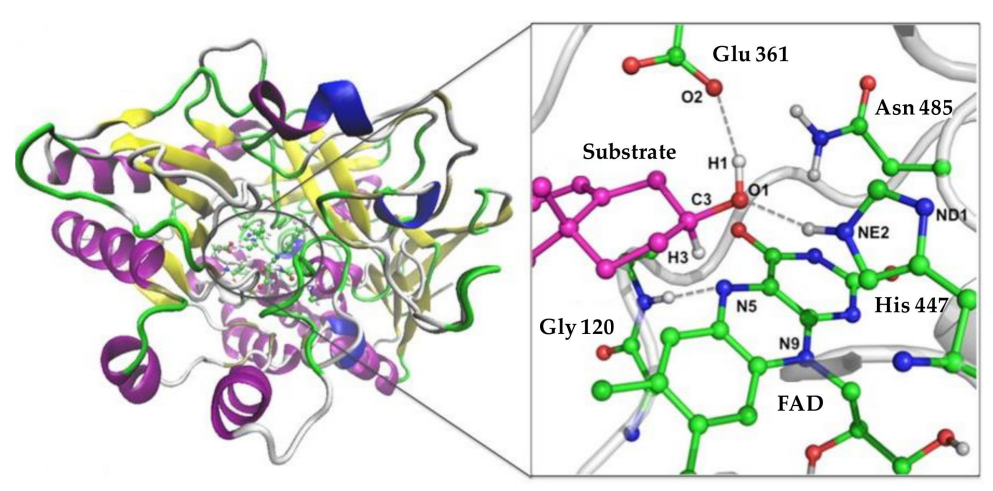

Figure 3. Structure of the cholesterol oxidase enzyme (pdb ID: 4U2T) with a close-up view of the active site showing the key catalytic residues. The substrate is shown in magenta and the dashed lines indicate the $\mathrm{H}$-bond interactions. Atomic color designation: $\mathrm{H}$, white; $\mathrm{C}$, green; $\mathrm{O}$, red; and $\mathrm{N}$, blue (Adapted from Yu et al., 2017 [72]).

The third step in the conversion of 4-cholesten-3-one to coprostanone includes a reduction of the $\Delta 4$ double bond into 3-oxo- $\Delta 4$-steroid by microbial 3-oxo- $\Delta 4$-steroid $5 \beta$-reductase (EC 1.3.1.3). Purification and activity monitoring of this reductase was performed initially in cecal contents from rats [68]. This process was found to involve a partial transfer of hydrogen from the $4 \beta$-position of NADH (Nicotinamide adenine dinucleotide) to the $5 \beta$-position of the steroid [73].

Based on transcriptomic studies using Bifidobacterium bifidum PRL2010, Zanotti et al. (2015) reported the up-regulation of three genes encoding for a putative cholesterol reductase in the presence of cholesterol [74]. The in silico study of these genes demonstrate that they display significant similarities with human cholesterol reductase ( $34 \%$ similar), thus, highlighting their potential involvement in the conversion of cholesterol to coprostanol [74]. A comparative study showed that all Bifidobacterium genomes contained genes $26 \%$ to $100 \%$ similar to Bifidobacterium bifidum reductase PRL2010. [74]. Recently, we analyzed the Eubacterium genomes, and no significant similarities were found with reductase genes [75]. The same study demonstrated that the Bacteroides sp. D8 genome showed $37 \%$ to $46 \%$ similarity with a cholesterol reductase-encoding gene from Bifidobacterium bifidum 
PRL2010 [75]. Overall, these results indicate that only few functional studies were focused on reductase, explaining the lack of mechanistic knowledge concerning this class of enzyme.

\section{Towards a Better Understanding of the Coprostanol Production Pathway}

Although cholesterol metabolism by gut microbiota has been known for almost a century, the genes and enzymes involved in the conversion of cholesterol to coprostanol are still largely unknown. Only a few coprostanoligenic bacteria have been isolated so far, and very few cholesterol-metabolizing strains are available $[42,45]$. Such strains are highly oxygen-sensitive, very difficult to grow, and seem to be non-dominant species within the human gut microbiota of high converters. Isolation of new cholesterol-metabolizing strains from the gut microbiota, and other ecological niches, will be of great interest to identify the genes involved in the reduction of cholesterol to coprostanol. Many approaches aiming at identifying bacterial functions are available, including activity-based screening and phenotypic assays [48]. With the availability of sequenced bacterial genomes and the diversity of coprostanol producing bacteria, comparative genomic approaches may also enable the identification of genes shared among coprostanoligenic microbial species [74]. The analysis of up-regulated genes in the presence of cholesterol using omic approaches can lead to the identification of candidate genes. Furthermore, functional metagenomics is a powerful way to characterize coprostanoligenic pathways from uncultured and metagenomic species. High throughput coprostanol analysis, coupled with targeted mutagenesis and genomic/metagenomic libraries, may provide additional mechanistic insights [76]. An in-depth, functional profiling of metagenomic data combined with biochemical insights may also help to achieve this goal.

\section{Conclusions}

Several reports stressed the key role of gut microbiota in cholesterol metabolism, essentially through the conversion of cholesterol to coprostanol. Microbial metabolic pathways remain poorly understood, as well as their relevance and distribution in the human gut microbiome. Significant efforts have been made to isolate new cholesterol-metabolizing bacteria and analyze their genomes. Unfortunately, these strategies did not allow the identification of genes responsible for coprostanol synthesis. Therefore, a critical need exists to set out new approaches and/or tools to analyze these microbial metabolic pathways and their associated genes. Deciphering the biochemical and structural features of the encoded proteins will be of interest to understand the properties of this reduction reaction and its importance for bacteria.

Author Contributions: A.K., M.B., H.M., A.J., N.A., S.S., E.M. and M.R. conceived the scientific ideas and designed the work; A.K., H.M., S.S., M.B. and M.R. performed the literature research and provided the first draft; A.K., A.J., N.A. and M.R. generated the figures; A.K., M.B., H.M., A.J., N.A., S.S., E.M. and M.R. discussed the work and edited the manuscript; E.M. and M.R. supervised the project. All authors reviewed the manuscript and provided critical feedbacks.

Funding: This work received a funding from the Microbiology and the Food Chain division (MICA) of the INRA institute through the metaprogramme MEM-Meta-omics and microbial ecosystems. AK, HM, NA, SS and AJ were supported by the project CMCU-PHC Utique ( $\left.{ }^{\circ} 14 \mathrm{G} 0816\right)$-Campus France $\left(\mathrm{n}^{\circ} 30666 \mathrm{QM}\right)$.

Acknowledgments: The authors would like to express their gratitude to S. Bolotine for his helpful discussion concerning the analysis of genomic sequences of coprostanoligenic bacteria.

Conflicts of Interest: The authors declare no conflicts of interest. 


\section{References}

1. Benjamin, E.J.; Virani, S.S.; Callaway, C.W.; Chamberlain, A.M.; Chang, A.R.; Rosamond, W.D.; Sampson, K.A.; Satou, G.M.; Shah, S.H.; Spartano, N.L.; et al. Heart Disease and Stroke Statistics-2018 Update: A Report from the American Heart Association. Circulation 2018, 137, e67-e492. [CrossRef] [PubMed]

2. Krobot, K.J.; Yin, D.D.; Alemao, E.; Steinhagen-Thiessen, E. Realworld effectiveness of lipid-lowering therapy in male and female outpatients with CHD: Relation to pre-treatment LDL-cholesterol, pre-treatment CHD risk and other factors. Eur. J. Cardiovasc. Prev. Rehabil. 2005, 1, 37-450. [CrossRef]

3. Groen, A.K.; Bloks, V.W.; Verkade, H.; Kuipers, F. Cross-talk between liver and intestine in control of cholesterol and energy homeostasis. Mol. Aspects Med. 2014, 37, 77-88. [CrossRef]

4. Lee, S.D.; Gershkovich, P.; Darlington, J.W.; Wasan, K.M. Inhibition of cholesterol absorption: Targeting the intestine. Pharm. Res. 2012, 29, 3235-3250. [CrossRef] [PubMed]

5. Chugh, A.; Ray, A.; Gupta, J.B. Squalene epoxidase as hypocholesterolemic drug target revisited. Prog. Lipid Res. 2003, 42, 37-50. [CrossRef]

6. Goldstein, J.L.; Brown, M.S. A century of cholesterol and coronaries: From plaques to genes to statins. Cell 2015, 161, 161-172. [CrossRef] [PubMed]

7. Hou, R.; Goldberg, A.C. Lowering low-density lipoprotein cholesterol: Statins, ezetimibe, bile acid sequestrants, and combinations: Comparative efficacy and safety. Endocrinol. Metab. Clin. N. Am. 2009, 38, 79-97. [CrossRef]

8. Gérard, P. Metabolism of cholesterol and bile acids by the gut microbiota. Pathogens 2014, 3, 14-24. [CrossRef]

9. Bhattacharyya, A.K. Differences in uptake and esterification of saturated analogues of cholesterol by rat small intestine. Am. J. Physiol. 1986, 251, 495-500. [CrossRef]

10. Sekimoto, H.; Shimada, O.; Makanishi, M.; Nakano, T.; Katayama, O. Interrelationship between serum and fecal sterols. Jpn. J. Med. 1983, 22, 14-20. [CrossRef]

11. Reddy, B.S.; Martin, C.W.; Wynder, E.L. Fecal bile acids and cholesterol metabolites of patients with ulcerative colitis, a high-risk group for development of colon cancer. Cancer Res. 1977, 37, 1697-1701. [PubMed]

12. Nomura, A.M.; Wilkins, T.D.; Kamiyama, S.; Heilbrun, L.K.; Shimada, A.; Stemmermann, G.N.; Mower, H.F. Fecal neutral steroids in two Japanese populations with different colon cancer risks. Cancer Res. 1983, 43, 1910-1913. [PubMed]

13. Dam, H. Historical introduction to cholesterol. In Chemistry, Biochemistry and Pathology; Cooked, R.P., Ed.; Academic Press: New York, NY, USA, 1958; pp. 1-14.

14. Liscum, L.; Underwood, K.W. Intracellular cholesterol transport and compartmentation. J. Biol. Chem. 1995, 270, 15443-15446. [CrossRef] [PubMed]

15. Simons, K.; Ikonene, E. How cells handle cholesterol. Science 2000, 290, 1721-1725. [CrossRef] [PubMed]

16. Sheng, R.; Chen, Y.; Yung Gee, H.; Stec, E.; Melowic, H.R.; Blatner, N.R.; Tun, M.P.; Kim, Y.; Källberg, M.; Fujiwara, T.K.; et al. Cholesterol modulates cell signaling and protein networking by specifically interacting with PDZ domain-containing scaffold proteins. Nat. Commun. 2012, 3, 1249. [CrossRef] [PubMed]

17. Ohvo-Rekilä, H.; Ramstedt, B.; Leppimäki, P.; Slotte, J.P. Cholesterol interactions with phospholipids in membranes. Prog. Lipid Res. 2002, 41, 66-97. [CrossRef]

18. Róg, T.; Pasenkiewicz-Gierula, M.; Vattulainen, I.; Karttunen, M. Ordering effects of cholesterol and its analogues. Biochim. Biophys. Acta 2009, 1788, 97-121. [CrossRef]

19. Do, T.Q.; Moshkani, S.; Castillo, P.; Anunta, S.; Pogosyan, A.; Cheung, A.; Marbois, B.; Faull, K.F.; Ernst, W.; Chiang, S.M.; et al. Lipids including cholesteryl linoleate and cholesteryl arachidonate contribute to the inherent antibacterial activity of human nasal fluid. J. Immunol. 2008, 181, 4177-4187. [CrossRef]

20. Tiangang, L.; Chiang, Y.L. Regulation of bile acid and cholesterol metabolism by PPARs. PPAR Res. 2009, $2009,501739$.

21. Walker, R.W.; Wun, C.; Litsky, W. Coprostanol as indicator of faecal pollution. Crit. Rev. Env. Control 1982, 12, 91-112. [CrossRef]

22. Singley, J.E.; Kirchmer, C.J.; Miura, R. Analysis of Coprostanol, an Indicator of Fecal Contamination; Environmental Protection Agency, Office of Research and Development: Washington, DC, USA, 1974; pp. 4-8.

23. Christie, W.W. Lipid Analysis: Isolation, Separation, Identification and Structural Analysis of Lipids, 2nd ed.; Pergamon Press: Oxford, UK, 1982. 
24. Saad, H.Y.; Higuchi, W.I. Water solubility of cholesterol. J. Pharm. Sci. 1965, 54, 1205-1206. [CrossRef] [PubMed]

25. Kanazawa, A.; Teshima, S.I. The occurrence of coprostanol, an indicator of fecal pollution in seawater and sediments. Oceanol. Acta 1978, 1, 39-44.

26. Freier, T.A. Isolation and Characterization of Unique Cholesterol-Reducing Anaerobes. Ph.D. Thesis, Iowa State University, Ames, IA, USA, 1991.

27. Li, L.; Buhman, K.K.; Hartman, P.A.; Beitz, D.C. Hypocholesterolemic effect of Eubacterium coprostanoligenes ATCC 51222 in rabbits. Lett. Appl. Microbiol. 1995, 20, 137-140. [CrossRef] [PubMed]

28. Li, L.; Batt, S.M.; Wannemuehler, M.; Dispirito, A.; Beitz, D.C. Effect of feeding of a cholesterol-reducing bacterium, Eubacterium coprostanoligenes, to germ-free mice. Lab. Anim. Sci. 1998, 48, 253-255. [PubMed]

29. Iqbal, J.; Hussain, M.M. Intestinal lipid absorption. Am. J. Physiol. Endocrinol. Metab. 2009, 296, E1183-E11894. [CrossRef] [PubMed]

30. Swell, L.; Troutec, J.; Hopper, J.R.; Fieldh, J.; Treadwell, C.D. Mechanism of cholesterol absorption. II. Changes in free and esterified cholesterol pools of mucosa after feeding cholesterol-4-C14. J. Biol. Chem. 1958, 233, 49-53. [PubMed]

31. Kellogg, T.F. On the site of the microbiological reduction of cholesterol to coprostanol in the rat. Lipids 1973, 8, 658-659. [CrossRef]

32. Setty, C.S.; Ivy, A.C. Intestinal absorption of coprostanol (coprosterol) in the rat. Am. J. Physiol. 1960, 199, 1008-1010. [CrossRef]

33. Wells, W.; Anderson, S.A.; Ma, Q. Lactose diets and cholesterol metabolism. I. Cholesterol absorption, coprostanol formation and bile acid excretion in the rat. J. Nutr. 1960, 71, 405-410. [CrossRef]

34. Rosenfeld, R.S.; Zumoff, B.; Hellman, L. Metabolism of coprostanol-C14 and cholestanol-4-C14 in man. J. Lipid Res. 1963, 4, 337-340.

35. Schoenheimer, R. New contributions in sterol metabolism. Science 1931, 74, 579-584. [CrossRef]

36. Koppel, N.; Maini Rekdal, V.; Balskus, E.P. Chemical transformation of xenobiotics by the human gut microbiota. Science 2017, 356, eaag2770. [CrossRef] [PubMed]

37. Kellogg, T.F. Steroid balance and tissue cholesterol accumulation in germfree and conventional rats fed diets containing saturated and polyunsaturated fats. J. Lipid Res. 1974, 15, 574-579.

38. Eyssen, H.J.; Parmentier, G.G.; Compernolle, F.C.; De Pauw, G.; Piessens-Denef, M. Biohydrogenation of sterols by Eubacterium ATCC 21408 nova species. Eur. J. Biochem. 1973, 36, 411-421. [CrossRef] [PubMed]

39. Brinkley, A.W.; Gottesman, A.R.; Mott, G.E. Growth of cholesterol-reducing Eubacterium on cholesterol-brain agar. Appl. Environ. Microbiol. 1980, 40, 1130-1132. [PubMed]

40. Brinkley, A.W.; Gottesman, A.R.; Mott, G.E. Isolation and characterization of new strains of cholesterol-reducing bacteria from baboons. Appl. Environ. Microbiol. 1982, 43, 86-89. [PubMed]

41. Freier, T.A.; Beitz, D.C.; Li, L.; Hartman, P.A. Characterization of Eubacterium coprostanoligenes sp. nov., a cholesterol-reducing anaerobe. Int. J. Syst. Bacteriol. 1994, 44, 137-142. [CrossRef]

42. Li, L. Characterization and Application of a Novel Cholesterol-Reducing Anaerobe, Eubacterium coprostanoligenes ATCC 51222. Ph.D. Thesis, Iowa State University, Ames, IA, USA, 1995.

43. Mott, G.E.; Brinkley, A.W. Plasmenylethanolamine: Growth factor for cholesterol reducing Eubacterium. J. Bacteriol. 1979, 139, 755-760. [PubMed]

44. Sadzikowski, M.R.; Sperry, J.F.; Wilkins, T.D. Cholesterol-reducing bacterium from human feces. Appl. Environ. Microbiol. 1977, 34, 355-362.

45. Gérard, P.; Lepercq, P.; Leclerc, M.; Gavini, F.; Raibaud, P.; Juste, C. Bacteroides sp. strain D8, the first cholesterol-reducing bacterium isolated from human feces. Appl. Environ. Microbiol. 2007, 73, 5742-5749. [CrossRef]

46. Snog-Kjaer, A.; Prange, I.; Dam, H. Conversion of cholesterol into coprosterol by bacteria in vitro. J. Gen. Microbiol. 1956, 14, 256-260. [CrossRef] [PubMed]

47. Crowther, J.S.; Drasar, B.S.; Goddard, P.; Hill, M.J.; Johnson, K. The effect of a chemically defined diet on the faecal flora and faecal steroid concentration. Gut 1973, 14, 790-793. [CrossRef] [PubMed]

48. Lye, H.S.; Rusul, G.; Liong, M.T. Removal of cholesterol by lactobacilli via incorporation and conversion to coprostanol. J. Dairy Sci. 2010, 93, 1383-1392. [CrossRef] [PubMed] 
49. Antharam, V.C.; McEwen, D.C.; Garrett, T.J.; Dossey, A.T.; Li, E.C.; Kozlov, A.N.; Mesbah, Z.; Wang, G.P. An Integrated metabolomic and microbiome analysis identified specific gut microbiota associated with fecal cholesterol and coprostanol in Clostridium difficile Infection. PLoS ONE 2016, 11, e0148824. [CrossRef] [PubMed]

50. Midtvedt, A.C.; Midtvedt, T. Conversion of cholesterol to coprostanol by the intestinal microflora during the first two years of human life. J. Pediatr. Gastroenterol. Nutr. 1993, 17, 161-168. [CrossRef] [PubMed]

51. Wilkins, T.D.; Hackman, A.S. Two patterns of neutral steroid conversion in the feces of normal North Americans. Cancer Res. 1974, 34, 2250-2254. [PubMed]

52. Veiga, P.; Juste, C.; Lepercq, P.; Saunier, K.; Beguet, F.; Gérard, P. Correlation between faecal microbial community structure and cholesterol-to-coprostanol conversion in the human gut. FEMS Microbiol. Lett. 2005, 242, 81-86. [CrossRef]

53. Macdonald, I.A.; Bokkenheuser, V.D.; Winter, J.; McLernon, A.M.; Mosbach, E.H. Degradation of steroids in the human gut. J. Lipid Res. 1983, 24, 675-700.

54. Gérard, P.; Béguet, F.; Lepercq, P.; Rigottier-Gois, L.; Rochet, V.; Andrieux, C.; Juste, C. Gnotobiotic rats harboring human intestinal microbiota as a model for studying cholesterol-to-coprostanol conversion. FEMS Microbiol. Ecol. 2004, 47, 337-343. [CrossRef]

55. Rosenfeld, R.S.; Fukushima, D.K.; Hellman, L.; Gallagher, T.F. The transformation of cholesterol to coprostanol. J. Biol. Chem. 1954, 211, 301-311.

56. Rosenfeld, R.S.; Hellman, L.; Gallagher, T.F. The transformation of cholesterol-3d to coprostanol-d. Location of deuterium in coprostanol. J. Biol. Chem. 1956, 222, 321-323.

57. Mott, G.E.; Brinkley, A.W.; Mersinger, C.L. Biochemical characterization of cholesterol-reducing Eubacterium. Appl. Environ. Microbiol. 1980, 40, 1017-1022. [PubMed]

58. Cuevas-Tena, M.; Alegría, A.; Lagarda, M.J. Relationship Between Dietary Sterols and Gut Microbiota: A Review. Eur. J. Lipid Sci. Technol. 2018, 120, 1800054. [CrossRef]

59. Rosenfeld, R.S.; Gallagher, T.F. Further studies of the biotransformation of cholesterol to coprostanol. Steroids 1964, 4, 515-520. [CrossRef]

60. Björkhem, I.; Gustafsson, J.A. Mechanism of microbial transformation of cholesterol into coprostanol. Eur. J. Biochem. 1971, 21, 428-432. [CrossRef] [PubMed]

61. Parmentier, G.; Eyssen, H. Mechanism of biohydrogenation of cholesterol to coprostanol by Eubacterium ATCC 21408. Biochim. Biophys. Acta 1974, 348, 279-284. [CrossRef]

62. Ren, D.; Li, L.; Schwabacher, A.W.; Young, J.W.; Beitz, D.C. Mechanism of cholesterol reduction to coprostanol by Eubacterium coprostanoligenes ATCC 51222. Steroids 1996, 61, 33-40. [CrossRef]

63. García, J.L.; Uhía, I.; Galán, B. Catabolism and biotechnological applications of cholesterol degrading bacteria. Microb. Biotechnol. 2012, 5, 679-699. [CrossRef]

64. Vrielink, A.; Ghisla, S. Cholesterol oxidase: Biochemistry and structural features. FEBS J. 2009, 276, 6826-6843. [CrossRef]

65. Cheetham, P.S.; Dunnill, P.; Lilly, M.D. The characterization and interconversion of three forms of cholesterol oxidase extracted from Nocardia rhodochrous. Biochem. J. 1982, 201, 515-521. [CrossRef]

66. Tomioka, H.; Kagawa, M.; Nakamura, S. Some enzymatic properties of 3beta-hydroxysteroid oxidase produced by Streptomyces violascens. J. Biochem. 1976, 79, 903-915. [CrossRef] [PubMed]

67. Fukuyama, M.; Miyake, Y. Purification and some properties of cholesterol oxidase from Schizophyllum commune with covalently bound flavin. J. Biochem. 1979, 85, 1183-1193. [PubMed]

68. Sojo, M.; Bru, R.; Lopez-Molina, D.; Garcia-Carmona, F.; Arguelles, J.C. Cell-linked and extracellular cholesterol oxidase activities from Rhodococcus erythropolis isolation and physiological characterization. Appl. Microbiol. Biotechnol. 1997, 47, 583-589. [CrossRef] [PubMed]

69. Vrielink, A.; Lloyd, L.F.; Blow, D.M. Crystal structure of cholesterol oxidase from Brevibacterium sterolicum refined at $1.8 \AA$ A resolution. J. Mol. Biol. 1991, 219, 533-554. [CrossRef]

70. Sampson, N.S.; Kwak, S. Catalysis at the membrane interface: Cholesterol oxidase as a case study. In Proceedings of the 3rd International Symposium on Experimental Standard Conditions of Enzyme Characterizations (ESCEC), Rudesheim Rhein, Germany, 23-26 September 2008; pp. 13-22.

71. Joseph, K.; Sampson, N.S. Cholesterol oxidase: Physiological functions. FEBS J. 2009, 276, 6844-6856. 
72. Yu, L.J.; Golden, E.; Chen, N.; Zhao, Y.; Vrielink, A.; Karton, A. Computational insights for the hydride transfer and distinctive roles of key residues in cholesterol oxidase. Sci. Rep. 2017, 7, 17265. [CrossRef] [PubMed]

73. Björkhem, I.; Gustafsson, J.A.; Wrange, O. Microbial transformation of cholesterol into coprostanol. Properties of a 3-oxo-4-steroid-5 beta-reductase. Eur. J. Biochem. 1973, 37, 143-147. [CrossRef] [PubMed]

74. Zanotti, I.; Turroni, F.; Piemontese, A.; Mancabelli, L.; Milani, C.; Viappiani, A.; Prevedini, G.; Sanchez, B.; Margolles, A.; Elviri, L.; et al. Evidence for cholesterol-lowering activity by Bifidobacterium bifidum PRL2010 through gut microbiota modulation. Appl. Microbiol. Biotechnol. 2015, 99, 6813-6829. [CrossRef]

75. Bolotine, A.; (INRA-paris-Saclay University, Jouy-en-Josas, France). Personal communication, 2017.

76. Lynch, A.; Crowley, E.; Casey, E.; Cano, R.; Shanahan, R.; McGlacken, G.; Marchesi, J.R.; Clarke, D.J. The Bacteroidales produce an $\mathrm{N}$-acylated derivative of glycine with both cholesterol-solubilising and hemolytic activity. Sci. Rep. 2017, 7, 13270. [CrossRef]

(C) 2019 by the authors. Licensee MDPI, Basel, Switzerland. This article is an open access article distributed under the terms and conditions of the Creative Commons Attribution (CC BY) license (http://creativecommons.org/licenses/by/4.0/). 